\title{
Integration between Transport Models and Cost-Benefit Analysis to Support Decision-Making Practices: Two Applications in Northern Italy
}

\author{
Paolo Beria $\left(\mathbb{D},{ }^{1}\right.$ Alberto Bertolin $(\mathbb{D})^{1}$ and Raffaele Grimaldi $\mathbb{D}^{2}$ \\ ${ }^{1}$ DAStU, Politecnico di Milano, Via Bonardi 3, 20133 Milano, Italy \\ ${ }^{2}$ Independent Researcher, Milano, Italy \\ Correspondence should be addressed to Alberto Bertolin; alberto.bertolin@polimi.it
}

Received 22 December 2017; Accepted 18 March 2018; Published 23 May 2018

Academic Editor: Marta Bottero

Copyright ( 2018 Paolo Beria et al. This is an open access article distributed under the Creative Commons Attribution License, which permits unrestricted use, distribution, and reproduction in any medium, provided the original work is properly cited.

\begin{abstract}
Decisions on transport plans and projects involve relevant public investments and may also determine radical changes in users' costs. Unfortunately, it is not rare that-especially at the strategic planning stage-decisions on alternative projects or scenarios are made on a qualitative basis or, at best, by setting some indicators and verifying how much they reach the politically decided targets (e.g., "increasing the use of bicycles by $10 \%$ "). In order to reduce subjectivity, a more quantitative and comprehensive approach to the evaluation is needed. A Cost-Benefit Analysis is a tool commonly used to assess public expenditure, but its application to mobility plans introduces further practical and theoretical complexities. In this paper, we will thus try to contribute to the topic of the assessment of both sustainable mobility transport plans and infrastructure projects by presenting the operative application of a CBA methodology that is, at the same time, theoretically coherent and rich in outputs to support the decision-maker. Moreover, we will discuss the possible use of GIS software in order to provide to the decision-makers a clear and immediate "picture" of the effects on the network linked to different scenarios. The structure is as follows. Firstly, we discuss the complexities involved in the evaluation of plans with respect to a single infrastructure. Secondly, we introduce the available approaches for the assessment of consumer surplus, namely, the Rule of Half and the logsum function method, which allow the perfect integration between CBA and transport models. Thirdly, we present, through some operative case studies, the methodologies applied to the assessment and the network effects visualization of the urban mobility plan and new infrastructures. Finally, we underline how we can make the results more understandable to politicians, policy-makers, stakeholders, and citizens and in general improve the transparency and the awareness of the choices.
\end{abstract}

\section{Introduction: Evaluating Transport Plans and Infrastructural Projects}

Modern transport plans try to achieve different objectives and, in general, try to obtain a more sustainable and inclusive transport system, as suggested by the recent European Sustainable Urban Mobility Plans (SUMPs) guidelines [1]. This is usually done by foreseeing, simultaneously, the improvement of existing transport services and infrastructure, together with the implementation of sustainable mobility policies. This also allows taking advantage of the benefits of policy packaging in terms of higher acceptability, effectiveness, and efficiency [2]. Among the available policies, we can recall the promotion of city walkability, the development of bike transport, road pricing, park pricing, technological investments on networks, vehicles, and communications, smart mobility, vehicle sharing projects, incentives, redefinition of fares structure, mobility credits, and so on. $[1,3,4]$.

When performing the evaluation of such complex plans, a mismatch occurs between the available assessment techniques and the contents and expectations of plans. In fact, the economic evaluation of transport investments is usually intended in terms of assessment of transport infrastructure, while plans include a broader range of actions, where expected environmental and social impact can play a dominant role in policy evaluation [5]. 
TABLE 1: Policy actions in a mobility plan and type of effect.

\begin{tabular}{|c|c|c|c|}
\hline Action/policy & Costs & Benefits & $\begin{array}{l}\text { Investment costs are dominant versus } \\
\text { other costs? }\end{array}$ \\
\hline $\begin{array}{l}\text { New infrastructure (public transport, roads } \\
\text { capacity) }\end{array}$ & PU, T & $\mathrm{pr}, \mathrm{C}, \mathrm{t}$ & Yes \\
\hline $\begin{array}{l}\text { New/modified services on existing } \\
\text { infrastructure }\end{array}$ & PU, t & $\mathrm{pr}, \mathrm{d}, \mathrm{t}$ & No \\
\hline Innovative mobility (sharing, pooling, etc.) & & pr, d, t & No \\
\hline Bicycle lanes, bike parking, bike sharing & PU, T & $\mathrm{pr}, \mathrm{d}, \mathrm{t}$ & Yes/No \\
\hline ITS, traffic management & PU, $t$ & pr, d, t & No \\
\hline $\begin{array}{l}\text { Restrictive policies, car-free zones, traffic } \\
\text { calming }\end{array}$ & $\mathrm{pr}, \mathrm{d}, \mathrm{t}$ & $\mathrm{d}, \mathrm{t}$ & No \\
\hline Park and road pricing & pr, d, t & PU, pr, d, t & No \\
\hline Public transport fares & $\mathrm{PU} / \mathrm{pr}, \mathrm{d}, \mathrm{t}$ & $\operatorname{Pr} / \mathrm{PU}, \mathrm{d}, \mathrm{t}$ & No \\
\hline
\end{tabular}

PU: public bodies; pr: private users; C: concentrated in space or limited to groups; d: diffused in space or spread among many users; T: punctual in time, lump sum; t: continuous in time.

The mismatch lies also in the evaluation tools commonly used to support the design of mobility plans and the consequent public decisions, which are substantially referable to

(i) Traditional Cost-Benefit Analysis (CBA), required practically everywhere to allocate public money for infrastructure investments, that is, in cases where the public decision is dominated by the alternative allocation of lump sums [6-8];

(ii) Multicriteria analyses (MCA) and Indicators-based assessments, used to structure and clarify the goals and the (possibly positive) effects of the actions of a plan, such as the foreseen decrease in car ownership or pollutants concentrations $[9,10]$.

In the assessment of a plan made of both "hard" (infrastructural) investments and "soft" policies, both traditional approaches may fail. In particular, a rigid CBA may not be able to catch all the effects of the plan $[7,8,11,12]$ and, in addition, provides too concise outputs to support the dialogue with public opinion and stakeholders [13]. On the other side, indicators and MCA are, by definition, not able to measure the efficiency of public expenditure, which represents a key element of public decisions [7, 8]. Some EU members state that, in order to include nonmonetized impacts in infrastructure projects or policy evaluation, they opted for MCA in which a CBA is contained $[14,15]$.

Moreover, one must consider that the "typical" scheme of lump sum public costs versus distributed private benefits is not always the case, especially with pricing or limitation policies. In these cases, the policy gives both advantages to some groups (e.g., public transport users) and disadvantages to others (e.g., car drivers), in some cases entailing no significant public expenditure. A decision on this kind of policy, which is not simply "adding" new transport supply for someone, should obviously take into account not only the benefits, but also the public and the private costs necessary to obtain them.

Table 1 provides an example of possible policy actions, with different spatial and time boundaries of their effects, which may be included and assessed in a complex urban mobility plan.

In plans, additive policies, such as new infrastructures whose costs are public and concentrated in time, coexist with restrictive policies, such as traffic calming, pricing, and so on, which changes mobility patterns through raising the private costs. These two extremes must be assessed in a coherent way, but their effects and economic mechanisms are substantially different.

Moreover, the effects act synergistically, so that modal shift is the effect of both the improvement of the destination mode (e.g., public transport) and the worsening of the origin mode (e.g., private road transport). When the existence of such complex cost and benefit structures in the assessment of plans or projects is recognised, theoretical and practical problems may arise. As already mentioned, approaches using only indicators and MCA are not satisfactory for evaluating the trade-offs of public expenditure. At the same time, CBA in the "simple" form, as suggested by numerous guidelines (e.g., $[16,17])$, is not sufficiently complex to handle the previously mentioned problems and, in addition, fails in effectively representing the distribution of effects [18], especially for non-win-win policies.

Lastly, especially when CBAs are implemented to investigate complex transport scenarios, problems can arise from the imbalance between expert knowledge and various stakeholders' expectations on their "pet-projects" [13]. In order to promote a constructive dialogue in the decision-making process, not only must CBAs be rigorous from a methodological point of view, but also their final and, possibly, intermediate results have to be both intuitive and effective for a general audience.

For such reasons, in this paper, we will contribute to the topic of decision-making for complex plans and projects in a threefold way:

(a) How to manage the consumer surplus from a theoretical viewpoint. While theoretical literature on methods is mature and clear, it does not appear helpful from the point of view of practical applications. On 
the other side, guidelines are often too simplistic to handle complex problems, or even misleading.

(b) How to practically calculate the consumer surplus for both a mobility plan and an infrastructural project based on transport model outputs.

(c) How to enrich the outputs of the evaluation in order to make the assessment useful to inform decisionmakers' choices.

The paper is structured as follows. Section 2 discusses the two correct ways to calculate consumer surplus, the Rule of Half and the logsum function method, underlining both their pros and cons and in which situations they are recommended. Section 3 illustrates how these two methods can be calculated, in practice, by means of a transport simulation model, and how to modify the general formula when an active mode is included in simulations. Section 4 presents two evaluation cases: Milan's Sustainable Urban Mobility Plan and the Milan Malpensa airport rail ring closure. Section 5 concludes.

\section{Calculating the Consumer Surplus}

CBA is a widely used and codified technique. The transformation into monetary values of the majority of variables taken into account in the analysis can be done in an intuitive way (investment costs, running costs, environmental benefits, taxation, etc.; see, e.g., $[16,17])$, but we cannot say the same for the consumer surplus. This component, especially when related to complex plans, may be misleading and concurring in the introduction of double counts or internal incoherencies $[19,20]$.

Many guidelines indicate three possible approaches to estimate the consumer surplus. In practice, their application is seldom discussed and the responsibility to choose among them is left to technicians. For example, in Italy the guideline provided by the Ministry of Transport [21] does not suggest the application of a specific method to calculate user surplus, while the Lombardy Region guidelines define the Rule of Half method as mandatory to evaluate infrastructural projects [22]. Nevertheless, the three methods return results that are not always comparable. In particular, the simplest approach, the generalised costs comparison, has results that are adequate only under very specific and seldom-present conditions [23]. The other two methods ensure a different level of robustness and precision and require different amounts of data but can both be suited to almost any application. In the following, we will illustrate these two latter methods, and we will underline when they are almost perfectly substitutable and when; on the contrary, we can expect considerably different outputs.

2.1. The Rule of Half ( $\mathrm{RoH}$ ) Method. The consumer surplus is defined as the difference between user willingness to pay to make a specific trip and the "price payed" to make it [24]. In transport, the "payed price" by each user to make a specific trip is codified in the so-called generalised cost (GC). The GC represents the monetary value that the user

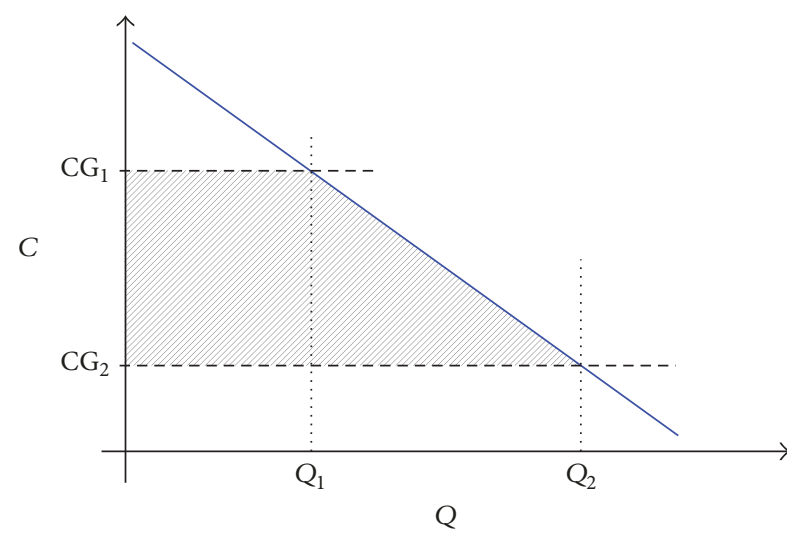

FIgURE 1: Representation of the Rule of Half (our elaboration).

associates with his overall trip experience, including out-ofpocket expenses (tolls and fares), operating costs of vehicles (in private transport), and consumed time. Other factors like discomfort, crowding, landscape, and more personal attitudes can also reduce or increase the GC of the same trip for different users (in the paper, we refer to the calculation of user surplus in terms of perceived (or private) costs, which-as we discussed in a former working paper [20] - requires some corrections to balance transfers (e.g., taxes and fares) among different parts of society; another relatively widespread approach, especially when the GC comparison is used, is to calculate the variation in user surplus directly in terms of social costs; the considerations made in this paper remain valid).

Thus, intuitively, the variation between the GC before and after a project or policy implementation will return the gain or loss in benefit (surplus) for a specific user even when he shifts between different means of transport.

Unfortunately, information on the single user trip experience is not always available. More realistically, when available, we can use a transport model to obtain the average generalised costs of groups of users (see Section 3), also in a very detailed way. The problem that arises is how to treat shifting users knowing only the GC average value and the total quantity of users in each group.

Traditionally, the most robust and used method to calculate the variations in user surplus when a transport model is not available is to hypothesize the unknown demand curve as a linear function between two points. These points, which are always known, are codified by the intersection between GCs and the total amount of users $(Q)$ before and after the project implementation $[16,19,20]$.

This hypothesis allows the application of the so-called Rule of Half. The area of the rectangle having base $Q_{1}$ (the number of existing users) and height $\mathrm{GC}_{1}-\mathrm{GC}_{2}$ (the reduction in generalised costs, that is, the unit benefit) represents the surplus variation of existing users. Similarly, the surplus of generated or shifted users is given by the area of the triangle having base $Q_{2}-Q_{1}$ (the number of new users) and the same height $\mathrm{GC}_{1}-\mathrm{GC}_{2}$ (Figure 1). 
The variation in user surplus is thus given by the area of a trapezius as in (1) (hence the name "of half"):

$$
\begin{aligned}
\Delta S_{\text {users }}= & \left(Q_{1}\right) \times\left(G_{1}-G_{2}\right)+\frac{1}{2}\left(Q_{2}-Q_{1}\right) \\
& \times\left(G_{1}-G_{2}\right) \\
\Delta S_{\text {users }}= & \frac{1}{2}\left(Q_{1}+Q_{2}\right) \times\left(G_{1}-G_{2}\right) .
\end{aligned}
$$

Due to its simplicity and the relatively reduced amount of data needed in the formula, this approach is very widespread. Any other method requires both estimating the GCs' absolute values, a much more difficult task, and knowing the GC of "origin" modes (the estimation of the absolute value of generalised costs is not a simple exercise without a transport model, especially in public transport and in active modes (walking and cycling); the related variation is instead usually made only of easily measurable items, like time savings and/or operating costs).

Moreover, this method, by treating the whole of induced users (i.e., both generated and shifted from other modes, paths, time of the day, etc.) in the same way and not needing the absolute values of the GCs, avoids all the problems linked to the generalised costs comparison approach. These problems are mainly determined by the impossibility of knowing the GC value for each single user [23].

2.2. The Logsum Function Method. The $\mathrm{RoH}$ assumes a certain distribution of users across average GCs. Depending on the required level of detail (and, of course, on the available data), analysing, by disaggregating as much as possible users in homogenous groups (i.e., in terms of geography, trip purpose, etc.) and applying the $\mathrm{RoH}$ to each group separately can minimise the error equal to the distance between the single user GC and the average group value.

Despite its methodology consistency, $\mathrm{RoH}$ returns an approximation of user surplus based on a "strong" preliminary assumption: a linear distribution between demand and GCs.

However, when a calibrated transport model is available, it is possible to use another method to assess the variation in user surplus, which gives a much more detailed representation of the benefits. By measuring, for all alternatives (modes), the variation in the composite utility (logsum) returned by the transport model, it is possible to calculate not only the average values of the GCs, but also their implicit distribution among users, thus having a more precise variation in user surplus [25].

Most transport models, in fact, estimate the share of users $[p]$ that will choose a transport mode $[m]$, on the origindestination pair [od], for the trip purpose $[s]$, using the multinomial logit formula described in (2) (if the model is based on a nested logit, this operation can be done on the first (higher) level of the logit; the GC represents the disutility of the trip) $[26,27]$. Parameter $\left[\lambda_{s}\right]$ is a calibrated value that maximizes the probability that the expected (simulated) modal share is coherent with the observed value (real data used in calibration) for the users travelling for the purpose group $[s]$.

$$
p_{\mathrm{od}|s| m}=\frac{e^{\lambda_{s} \cdot \mathrm{GC}_{\mathrm{od}|s| m}}}{\sum_{m} e^{\lambda_{s} \cdot \mathrm{GC}_{\mathrm{od}|s| m}}} .
$$

Thus, the unitary surplus variation is equal to the difference in the composite utility (given by the logarithm of the denominator of the logit formula (thus the name, "logsum"), divided by the calibration parameter), before and after projects and/or policies implementation. Once we multiply this unitary value for the number of trips related to each single purpose, we obtain the user surplus variation linked with that trip purpose $[\Delta S][25,28-30]$ (Bates [31] states that "with a logit model, there is a closed form solution for the integral under the demand curve," which is the surplus).

$$
\begin{aligned}
& \Delta S_{\mathrm{od} \mid s} \\
& =\operatorname{trips}_{s} \cdot \frac{1}{\lambda_{s}} \\
& \qquad\left[\left(\ln \sum_{m} e^{\lambda_{s} \cdot \mathrm{GC}_{1, \mathrm{od}|s| m}}\right)-\left(\ln \sum_{m} e^{\lambda_{s} \cdot \mathrm{GC}_{2, \mathrm{od}|\mathrm{s}| m}}\right)\right] .
\end{aligned}
$$

The sum of these variations for all the user groups obviously gives the total variation in consumer surplus associated with the scheme or policy.

If we expect generated demand to appear in the postproject scenario, and we want to keep using the logsum approach, Bates [31] suggests applying the Rule of Half to the standard logsum formula (4):

$$
\begin{aligned}
\Delta S_{\mathrm{od} \mid s} & \\
= & \frac{1}{2} \cdot\left(\operatorname{trips}_{1, s}+\operatorname{trips}_{2, s}\right) \cdot \frac{1}{\lambda_{s}} \\
& \cdot\left[\left(\ln \sum_{m} e^{\lambda_{s} \cdot \mathrm{GC}_{2, \mathrm{od}|s| m}}\right)-\left(\ln \sum_{m} e^{\lambda_{s} \cdot \mathrm{GC}_{1, \mathrm{od}|s| m}}\right)\right] .
\end{aligned}
$$

Despite being well-discussed in the literature quoted above, the logsum function method has been barely seen from an applicative point of view, when real projects and plans must be practically assessed. The following part of this paper tries to go more deeply in this direction (a more detailed discussion on differences between logsum and Rule of Half methods is presented in Maffii et al. [32], Cascetta [25], Geurs et al. [33], Grimaldi and Beria [20], and Bates [31]).

\section{Consistent Integration between Planning, Modelling, and Assessment}

3.1. Benefit from a Direct Integration of CBA and Transport Models. The most complex aspect to model in a CBA is the demand curve and its relationship with the replaced assets when generated demand is present. In the transport sector, the demand generated by a certain project is the sum of the new demand induced by the lower transport cost (people who now travel and who did not travel before, given their lower 
level of willingness to pay) and the demand attracted from other means of transport.

Generally, transport problems are faced with four-stage multimodal models (guidelines from Lombardy Region [22, p. 18] and the Italian Ministry of Transport [21, p. 30] define the use of multimodal transport models to evaluate infrastructural projects as mandatory). These models allow both the distribution of the existing and generated (induced and/or attracted) demand between OD relations and, considering the relative generalised costs that determined the choices, the calculation of users' paths.

Within the four-stage models, the modal choice can be assimilated to the application of a demand curve. A certain perceived cost (according to the CBA formulation) or generalised cost (according to the modelling formulation), corresponds to a certain quantity consumed. Therefore, the integration between models and CBAs allows greater precision (ensured by the model) in determining the costs for all users on the entire network modelled (instead of considering separately the users on specific segments of the network) and a perfect match between model and evaluation.

In conclusion, while without a model, the CBA must necessarily be based on rather strong assumptions (invariance of the demand or, in the case of demand generated or shifted, assuming a linear trend for the demand curve); with a model, the descriptions of both demand and user surplus variation will be much more detailed. Moreover, parameters such as the value of time can be directly those of the calibrated model.

3.2. Extracting Generalised Costs. When a transport model is available, it is relatively easy to extract the GCs directly from it, guaranteeing a complete consistency between the model and the following Cost-Benefit Analysis. The GCs derived this way can be used both with the Rule of Half and with the logsum method.

To obtain GCs, it is sufficient to extract the systematic utilities used by the model, which is usually constructed like in (5) (with systematic utility $V$ we mean, according to the definition by Cascetta [25], "the mean or the expected value of the utility perceived among all the users with the same choice context"; the perceived utility $U$ is given by the sum of the systematic utility $V$ and the random residual $\varepsilon$ (which represents the deviation of the single user with respect to the average value): $U=V+\varepsilon$ ).

$$
\begin{aligned}
V_{\text {od }|s| m}= & \beta_{s \mid m}^{\text {Time }} \cdot \text { Time }+\beta_{s \mid m}^{\text {Cost }} \cdot \text { Cost } \\
& + \text { Other_components. }
\end{aligned}
$$

If we divide the systematic utility by the parameter related to its monetary component, we express it in monetary terms representing the monetary trade-off that users attribute to their trips, which is the GC.

$$
\mathrm{GC}_{\mathrm{od}|s| m}=\frac{V_{\mathrm{od}|s| m}}{\beta_{s \mid m}^{\operatorname{Cost}}} .
$$

Some transport modes might not be associated with any direct monetary component (e.g., walking and cycling). There is a way to overcome the issue, though with some loss of consistency (see, e.g., [34] or [29]). We divide the systematic utility by the time parameter (which is always present) instead of by the cost one, thus deriving a generalised time instead of the generalised cost.

$$
\mathrm{GT}_{\mathrm{od}|s| m}=\frac{V_{\mathrm{od}|s| m}}{\beta_{s \mid m}^{\text {Time }}} .
$$

Then we multiply this generalised time by an exogenous value of (in-vehicle) time (VoT), obtaining the generalised cost.

$$
\mathrm{GC}_{\mathrm{od}|s| m}=\mathrm{VoT} \cdot \mathrm{GT}_{\mathrm{od}|s| m} .
$$

When the GCs are estimated, we can directly apply the formulas of the surplus variation, discussed in Section 2. It must be noticed that this passage is done at the highest level of disaggregation: per origin-destination pair (od), travel purpose $(s)$, and mode $(m)$. This is a computational burden, involving even millions of operations if the study area is divided into hundreds or thousands of zones, like in urban or regional areas. However, this disaggregation allows for enriching the readability and completeness of outputs.

3.3. Presenting the Results. In fact, a nonsecondary aspect deals with the outputs of the analysis. Backing the surplus calculation methods with a calibrated model and working at the origin-destination pair allows the representation of the benefits geographically, and not only in an aggregate way. This kind of representation may be a useful complement to the aggregate CBA indicators (NPV, NBIR, B/C, IRR; [16]) both in the consultation phase and, ultimately, in making better decisions.

Indeed, the network effects visualization, thanks to a GIS software, of a proposed project or policy allows for foreseeing which parts of the territory (and, consequently, which citizen groups) will gain or lose more if that action takes place.

In the next section, we present the methodologies applied for the assessment and network effects visualization of the sustainable urban mobility plan of the Milan municipality (see Section 4.1) and the proposed rail ring of the Malpensa airport (see Section 4.2). Due to their specificities, for the plan evaluation, we utilized the logsum method, which assures that nonadditive policies do not bring the risk of double counts, and the $\mathrm{RoH}$ one for the rail project.

\section{Theory Application: Two Case Studies}

4.1. Milan's Sustainable Urban Mobility Plan. For the assessment of the new Milan's Sustainable Urban Mobility Plan [35] we interfaced the simulation model developed by the transport authority (AMAT), with the assessment procedure, based on the interaction between a database and spreadsheet software. The transport model has been used extensively in the past years to plan all transport decisions in the city and can rely on solid datasets of observations, used for the calibration. Not only CBA, but also The Strategic Environmental Assessment of Milan's SUMP was based on the same transport model outputs. However, these two evaluations 


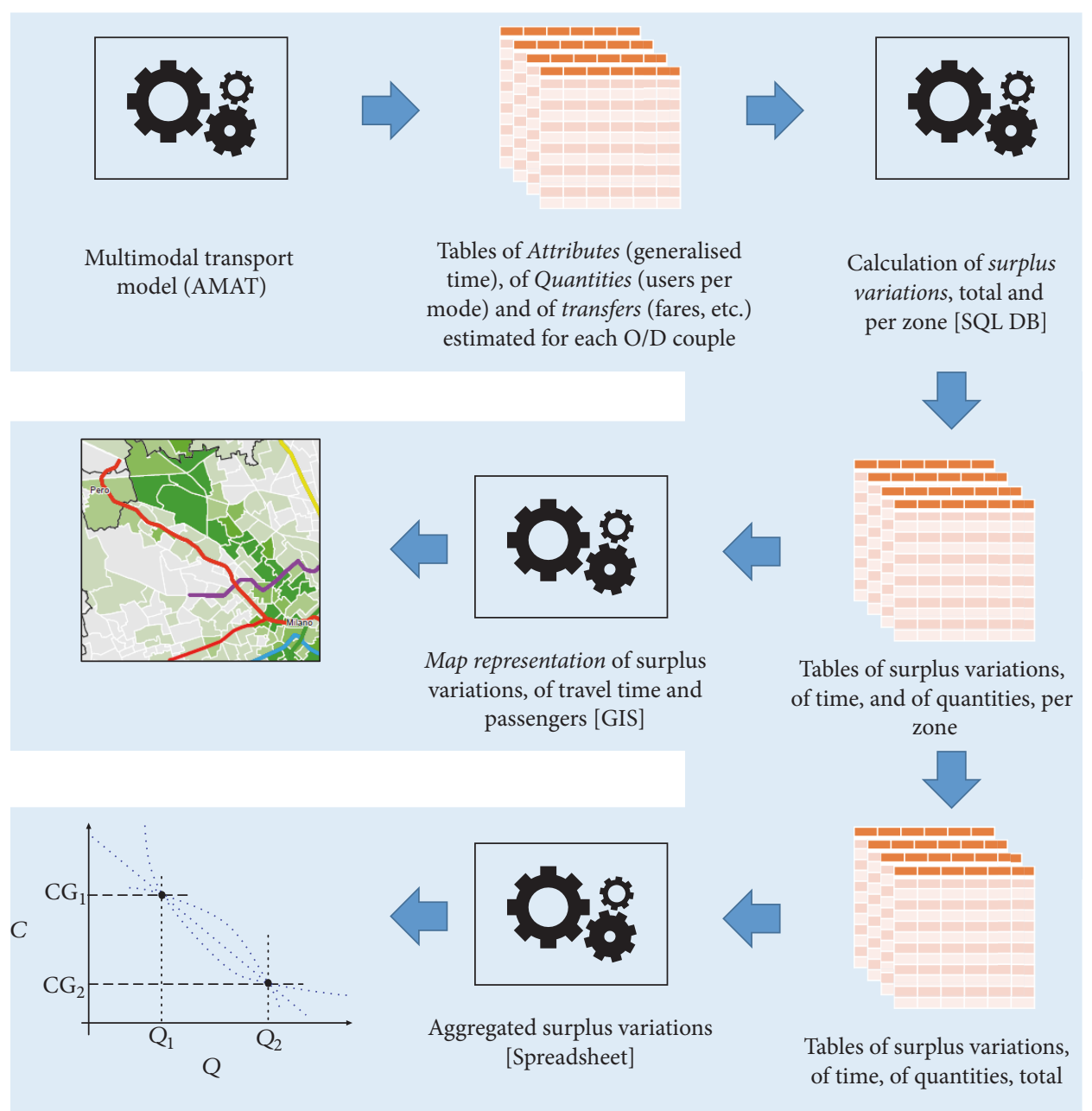

FIgURE 2: The assessment procedure implemented for the Milan's Sustainable Urban Mobility Plan (SUMP).

differ for some assumptions on input data (e.g., CBA, in the environmental effects calculation, considers, for the year 2024, an equal distribution between the total number of Euro V and VI vehicles, while the latter defines the vehicle's fleet starting from a regression model on gasoline sale trends). However, the overestimation "error" magnitude is contained and does not affect the overall CBA result [36, pag. 112].

A schematic representation of the algorithm developed for SUMP scenario's assessment is depicted in Figure 2.

The transport model provided the generalised cost components of each origin-destination (OD) pair for five different travel purposes (plus the "back-to-home" purpose) and for four modes (car, motorbike, public transport, and active modes). Each segment of the simulated mobility is associated with a set of calibrated $\beta$ coefficients (5), including the values of time (per trip purpose and per mode). In addition, the model provides the quantities, in terms of passengers/users during the peak hour, for every mode on each OD pair, allowing us to calculate the mode-shifting users. Finally, the model output also includes the data used to correct the monetary transfers in the CBA, in particular the paid fares, the parking tolls, the road pricing tolls, the driven $\mathrm{km}$ (useful to calculate the fuel duties paid).

Overall, the output consists of a database file with tables of attributes (generalised time), quantities (amount of users), and transfers (fares, tolls, and taxes) per 390,452 origin-destination pairs and $24(4 \times 6)$ mode and travel purpose combinations. By means of SQL procedures, we estimated the surplus variation using the logsum method (as described in Section 2.2). It must be noticed that the core calculations are done at the highest disaggregation level, that is, per OD pair, mode, and travel purpose. Later, we proceeded with the aggregation of the results in 829 origin and destination zones, using the same zoning of the model. The same thing has been done for all attributes, quantities, and transfers.

Once the aggregation is done, the datasets become more manageable with other software programs. The procedure is then interfaced with a spreadsheet software for the CBA and with a GIS software to produce cartographical representations of the main variables.

The entire process has been applied for 51 explorative scenarios. For this reason, we put particular care into automating 


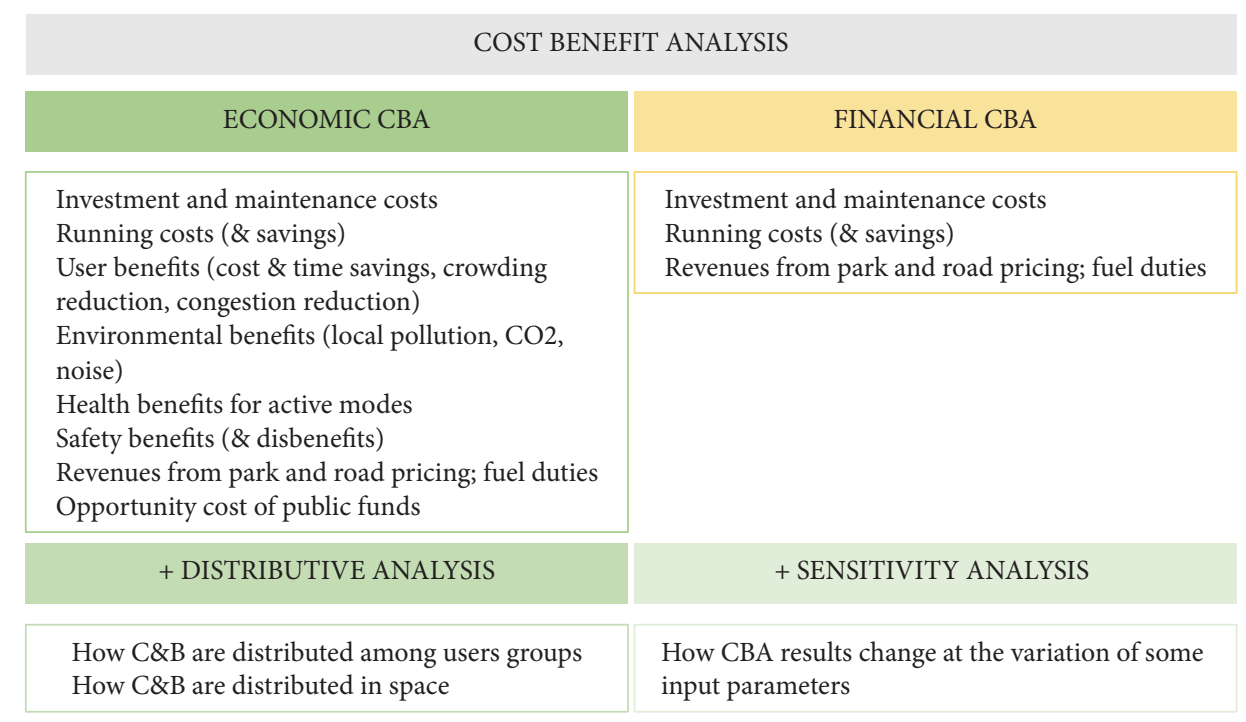

Figure 3: Cost-Benefit Analysis components.

the procedure with scripts. At the same time, we track all the intermediate results throughout every step to facilitate debug procedures. Some controls have been introduced intermediately to manually check the correctness of the results. The process also pointed out some local inconsistencies of the transport model, which have been corrected.

The CBA has been done within a spreadsheet software, in the two variants of Economic CBA and Financial CBA. The elements included are listed in Figure 3, and the indicators calculated are the Net Present Value (NPV), the Net Benefit over Investment Ratio (NBIR), and the Benefit over Cost Ratio (B/C).

In addition, we also developed in the same environment the distributive analysis module (disaggregating the costs and the benefits into six user categories, plus the nonusers, the State, and the Local Administration) and a simple Sensitivity Analysis, testing automatically the effects of user surplus estimation, investment cost, and running costs on results.

The CBA, shortly described here, was directly included in the planning process as suggested in European guidelines [1]. It is worth mentioning because this represents the first case in Italy. In fact, it was only in 2015 that the regional government, within its guidelines, imposed the CBA as mandatory to assess transport projects [22] and, at the national level, this evaluation tool became compulsory one year later [21].

4.1.1. Scenarios. In a preliminary phase, planners, stakeholders, and politicians selected, among all the actions included in previous planning documents and/or indicated by citizens, 51 explorative scenarios to be assessed via CBA. This preselection was carried out by choosing, according to the political goals, the most effective alternative between comparable projects facing a single problem.

The selected policies and projects were heterogeneous in nature, from heavy infrastructural investment (i.e., new metro lines) to punctual traffic calming solutions (i.e.,
TABLE 2: SUMP explorative scenarios.

\begin{tabular}{lc}
\hline Explorative scenario & $\begin{array}{c}\text { Number of subscenarios } \\
\text { (alternative options) }\end{array}$ \\
\hline $\begin{array}{l}\text { Previous land use plan (PGT) } \\
\text { infrastructure }\end{array}$ & 3 \\
Metro line 1 extension & 3 \\
Metro line 2 extension & 5 \\
Metro line 3 extension & 3 \\
Metro line 4 extension & 4 \\
Metro line 5 extension & 3 \\
New Metro line 6 & 3 (explorative paths) \\
Tram 7 extension & 4 \\
Tram 24, 27, and 178 extensions & $2+1$ \\
Reorganisation of tram lines in the city & 1 \\
centre & 7 \\
New urban stations to support rail & 1 \\
"circle line" services & 2 \\
Change in a suburban rail line path & 1 \\
Extension of bike lanes & 4 \\
30 km/h speed limit areas & 2 \\
Road pricing (Area C) extension & \\
Actions to increase commercial speed \\
of surface public transport
\end{tabular}

$30 \mathrm{~km} / \mathrm{h}$ speed limit areas). Table 2 provides an overview of all the scenarios considered in the analysis.

The aim of this explorative evaluation was to identify those actions that returned positive CBA indicators or, in case of negative performances, under which conditions it was possible to reduce their negative socioeconomic impact. For example, in the case of the $30 \mathrm{~km} / \mathrm{h}$ speed limit areas, negative indicators were returned when this action was assessed alone. 


\section{1: scenario name}

2: socio-economic costs \& benefits of the project (qualitative \& quantitative description, monetised present value)

3: graphical representation of costs and benefits

4: financial analysis - 2024 cash flow

5: CBA Indicators, divided in «base» and «extended»

6: Issues not quantified in the CBA and discussed qualitatively:

$\begin{array}{ll}\text { i. } & \text { Crowding, quality } \\ \text { ii. } & \text { Reliability } \\ \text { iii. } & \text { Parking space in the city } \\ \text { iv. } & \text { Urban landscape } \\ \text { v. } & \text { Land value } \\ \text { vi. } & \text { Externalities during construction } \\ \text { vii. } & \text { Risk of cost overrun }\end{array}$

7: distributive analysis - impacts on groups

8: sensitivity analysis

9: summary of the results and short comment

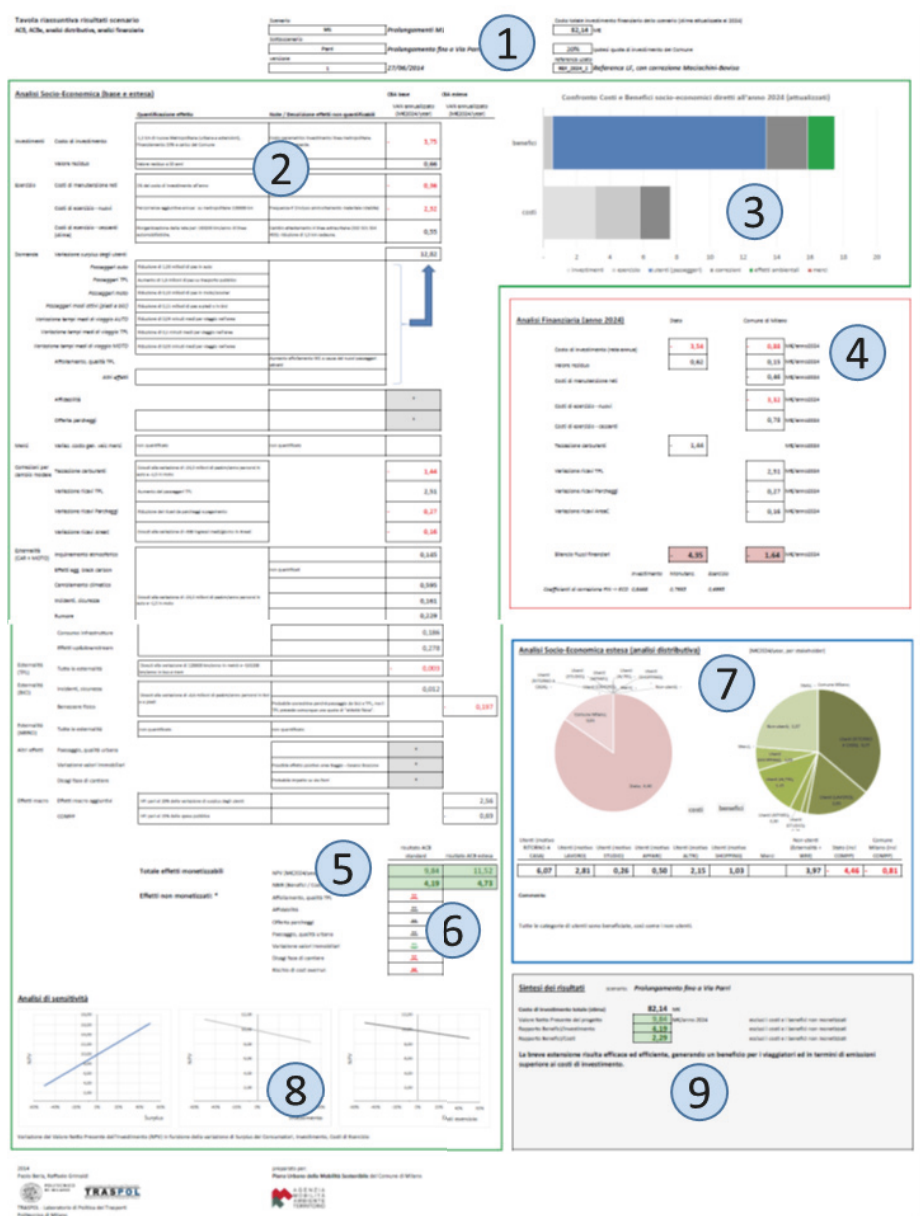

Figure 4: An example of Appraisal Summary Table organisation.
This intermediate result was a consequence of the reduction in road capacity and, consequently, an increase in congestion and travel time for private vehicle users. However, the same policy, evaluated in combination with other actions aimed at promoting a modal shift in favour of public transport, was associated with a positive impact in terms of user surplus.

At the end of this explorative phase, all positively assessed actions have been included in the final Plan Scenarios and evaluated together. This last scenario does not represent just a sum of all the positive/negative effects of the explorative ones, but takes into consideration the interdependency between the different actions within them.

4.1.2. Representing the Results. Thanks to the previously mentioned procedure, we were able to draw semiautomatically the outputs for the numerous scenarios. Moreover, final documents and analyses clarify all the main aspects that should be considered for the decisions, not limited to the sole aggregate CBA indicators (NPV, NBIR, and B/C). This result is fundamental in order to simplify the decision process of City Council, allowing different stakeholders to potentially revise their goals on the basis of a transparent and consistent analytical process.
To do that, all the intermediate and final results of the scenarios were presented through the following outputs.

(i) An Appraisal Summary Table, directly inspired by the ones used in the UK [37]

(ii) A Book of Maps, visualizing on a cartographic basis the effects of the hypothesis on users' behaviours and socioeconomic variables.

The first output included the socioeconomic assessment, the financial assessment, the distributive analysis, and a summary of the results complemented with some general comments (Figure 4).

Due to the different nature of the actions taken into consideration, we provided a double version of the Net Present Value (NPV), the Net Benefit over Investment Ratio (NBIR), and the Benefit Cost Ratio (B/C), calling them, respectively, "base" and "extended." The first set is based on a reliable quantification of all the monetized effects related to the single scenario implementation (investment, user surplus, externalities, etc.). The other set (extended), on the contrary, was an attempt to quantify, from an economic viewpoint, effects related to "soft" mobility policies such as health benefits for active modes, the opportunity cost of 
public funds, and an approximation of the possible wider economic effects. In fact, in these cases, these aspects can be considered as the most relevant, and a CBA that does not include them is mainly incomplete. However, due to objective difficulties in quantifying some of these effects, we introduce these indicators mainly to underline a possible positive or negative threshold in comparison with those of the first set. For example, on health benefits related to bicycle users, different sources provide very variable values. From

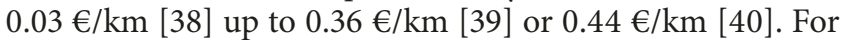
our analysis, we considered a weighted average value of 0.365 $€ / \mathrm{km}$. Moreover, other nonmonetary elements were returned only in a qualitative way (similar to what Sager [12] describes as a "narrow CBA").

Our aim, in fact, was to provide the decision-makers with not only a synthetic "number" to quantify the goodness of an action, but also a set of tools, giving politicians a certain level of informed discretion on the final decision.

The second output (Book of Maps) included, for each scenario, 24 cartographies showing the variations, both in absolute values and as a percentage, of user surplus, passengers per means of transport, and travel times and distances. Data was aggregated once per zone of origins and subsequently on destinations, allowing a complete visualization of the network effects connected to single scenarios.

This detailed output allows us to depict, for example, that users obtaining benefit from a metro or tram line extension are not only those citizens living or working next to it, but also users of other zones, related to different means of transport, benefiting from road decongestion. Similarly, this output is useful in directly visualizing the modal shift's spatial extension.

This tool is particularly effective in underlining unbalanced situations between different parts of the city (i.e., local benefit or, on the contrary, surplus loss due to punctual actions) and giving hints to policy-makers on how to address specific situations.

4.1.3. How Assessment Changed the Decisions. This approach proved to be a fundamental support for the redefinition of the strategic objectives of the public administration regarding the new type of mobility to sustain the future growth of the city. Through the combination of the aggregate results and benefits distribution maps, we were able to quantitatively effect a change of vision for the decision-maker from a traditional transport plan based on new "heavy" underground infrastructures to a plan made of punctual and cheaper actions homogeneously diffused on the entire Milanese public transport network.

For example, the first scenario considered the transport lines envisaged in the previous Milanese land use plan (PGT). This huge plan hypothesized the creation of 6 new highperformance lines for a total length of $77.3 \mathrm{~km}(56.1 \mathrm{~km}$ of metro lines and $21.2 \mathrm{~km}$ of tram lines), providing one run every 3 minutes per direction. In the evaluation, metro lines have been studied once as traditional heavy lines and once as automatic lines, having a higher investment but lower operating costs.
The main results of this new network were

(1) an increase in user surplus of $209 \mathrm{M} € /$ year;

(2) a reduction in bus operating costs of $47.6 \mathrm{M} € /$ year;

(3) an increase in public transport revenues of 25.6 M€/year;

(4) a reduction in negative externalities (accident, environment, and climate change) of $12.1 \mathrm{M} € /$ year.

However, these apparently good outcomes are not capable of counterbalancing the investment, operating, and maintenance costs of the new infrastructure and services. The Benefit/Cost ratio results are 0.80 for the conventional heavy metro version and 0.86 for the automatic light metro. The financial impact for the public budget would exceed $330 \mathrm{M} € /$ year.

In comparison, we tested a scenario based on a generalised speeding up of the entire overground (bus and tram) public transport, mainly through traffic light coordination and intersections redesign. The interventions hypothesized in the simulation consist of

(1) an increase in the commercial speed of some tram line up to $18 \mathrm{~km} / \mathrm{h}$ in the most congested part of the city;

(2) an increase of $10 \%$ in the commercial speed of all other bus and tram lines;

(3) the reintroduction of 3 circular bus and tram lines around the city centre;

(4) the implementation of the new peripheral tram line in the northern part of the Milan municipality.

As for the PGT scenario, the result in terms of user benefit was definitely positive (221 M€/year), but the Benefit/Cost ratio was outstandingly higher (above 15), considering an investment cost of $200 \mathrm{M} €$.

From the distributive point of view, the traditional metro extension scenario (Figure 6) and the cheaper speedup scenario (Figure 5) perform similarly. The latter gives homogeneous benefits to almost all zones of the city, while the metro extension presents some more inhomogeneity, with some zones largely benefited and others just marginally.

In conclusion, if the schematic goals of speeding up the public transport network are actually realized, their effect would be enormously positive and equal to that of six new high-frequency mass transit lines. The margin of benefit of this scenario is such that even obtaining only a fraction of the increase in commercial speed simulated can ensure a positive overall outcome.

This type of comparison is useful for testing, and potentially reorienting, decision-makers' vision and strategies, on which plans were founded. Also thanks to these comparative results, City Council decided to renounce a growth based on new "heavy" and costly infrastructure and, nowadays, the Milanese transport authority is working on punctual interventions that are able to ensure higher overground public transport commercial speeds. 


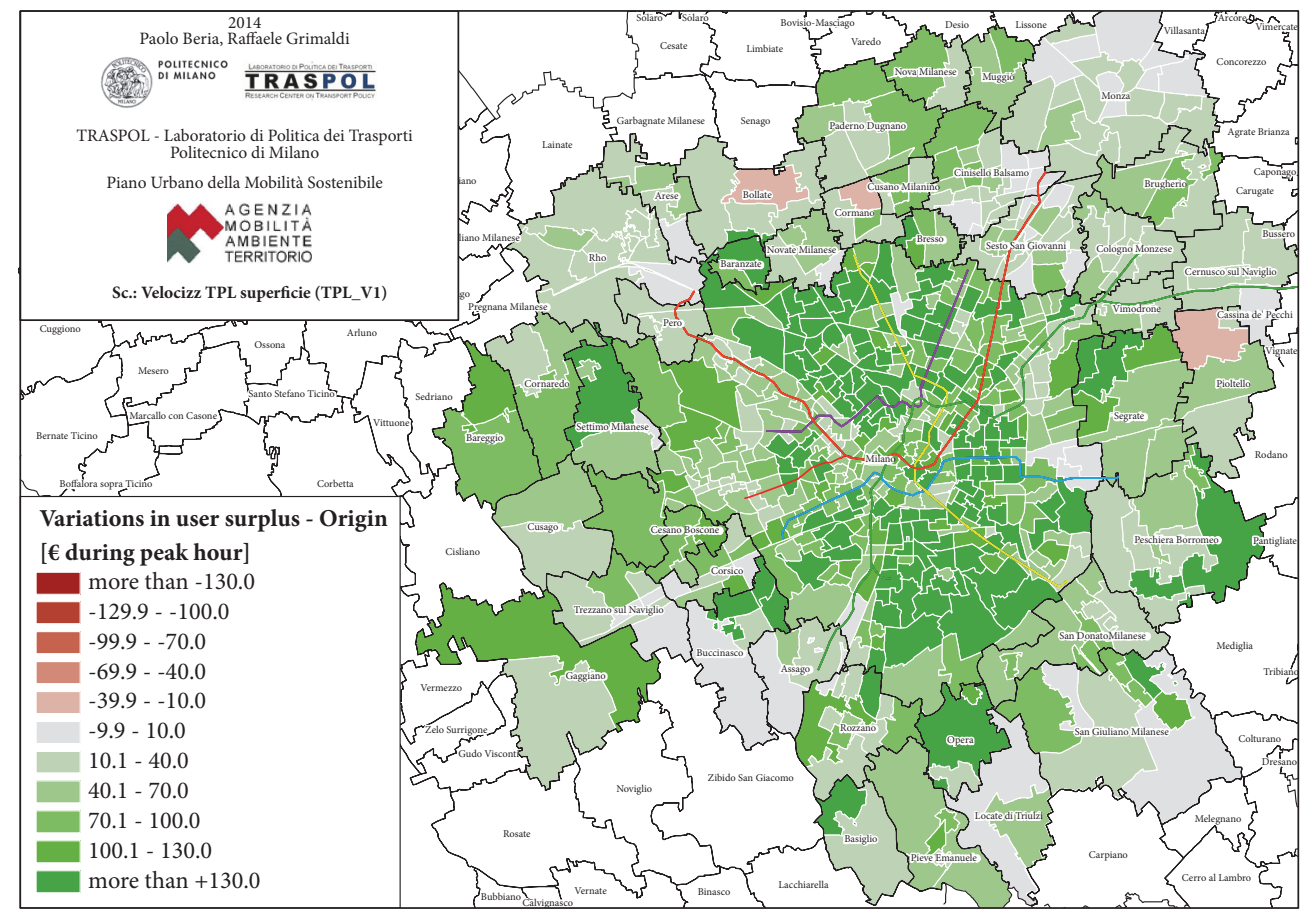

FIGURE 5: Variation in consumer surplus due to the generalised speeding up of the entire overground public transport ( $€$ in the morning peak hour; our elaboration).

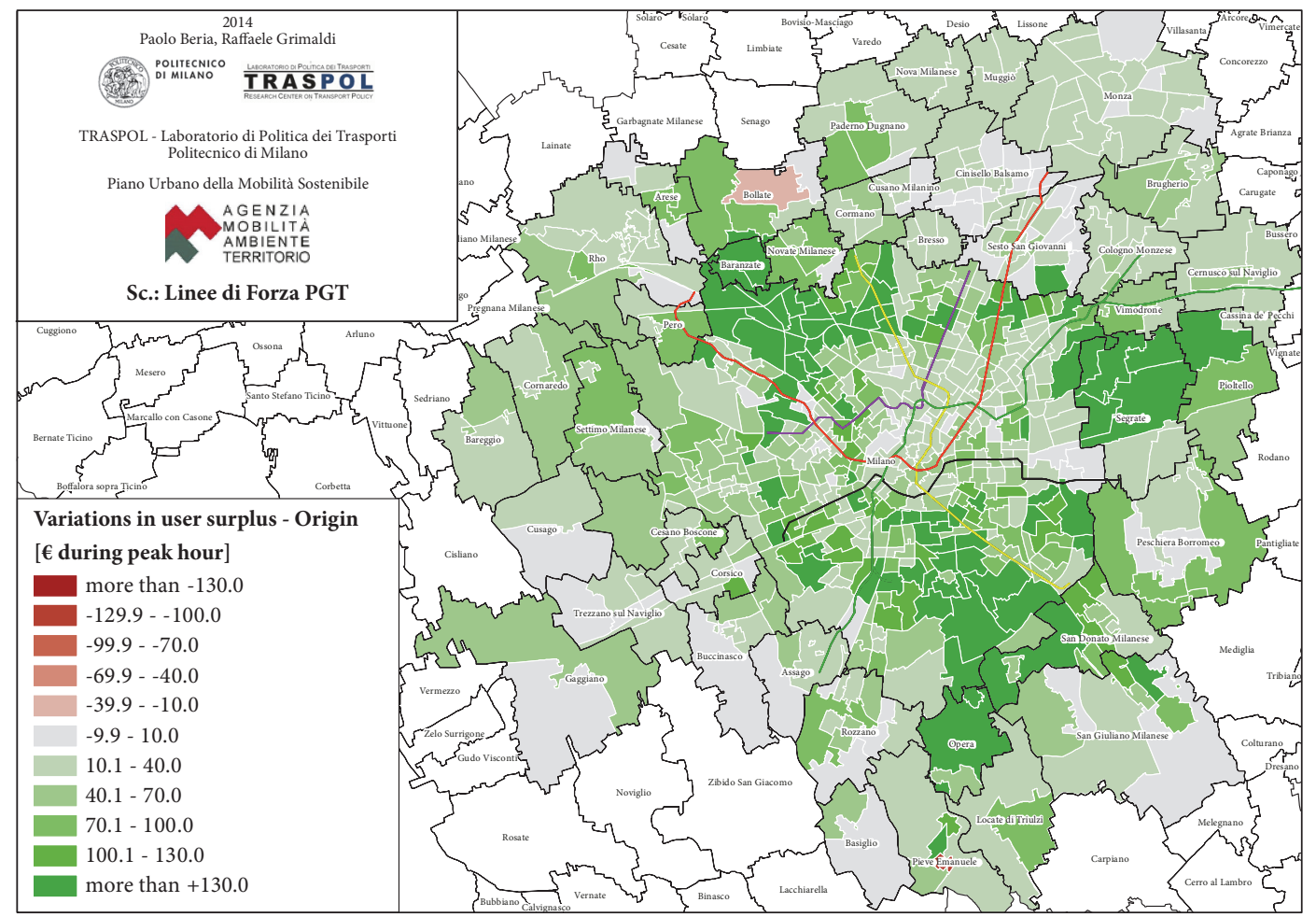

FIGURE 6: Variation in consumer surplus due to the 6 new high-performance public transport lines envisaged by the PGT ( $€$ in the morning peak hour; our elaboration). 
4.2. The Rail Connection between Malpensa Terminal 2 and the Simplon Line. The project presented by the Lombard railway company (FerrovieNord S.p.A.) and the airport manager of Milano Malpensa and Milano Linate (SEA S.p.A.) proposes an extension of the existing rail tracks from Malpensa airport's terminal 2 to Gallarate railway station, located on the Simplon rail line. The aim of this new connection is to increase the number of direct services, both national and international, stopping at the airport. Due to the relocation of actual services on the new tracks, the project allows the release of capacity on the Simplon rail axis, thus enabling the regional government to increase frequencies of some suburban services. This project was the very first application of the regional and national guidelines, recently issued [21, 22].

Similar to what was presented for the previous case, for the CBA assessment, we interfaced the transport model, developed by the Lombardy Region, with the evaluation procedure, developed with a database and spreadsheet software. In this case, the transport model was developed quite recently (it was used for the first time in 2015 to evaluate the Regional Program on Mobility and Transport). For this reason, in the preliminary evaluation phase, a higher effort was devoted to debug and calibration procedures (see below). These operations were made possible by the geographical visualizations of surplus variation effects through the interactions with a GIS software (see Section 4.2.2).

Given that the expected effects mainly spread at the regional level, model zoning, user characteristics, and transport modes presented a higher level of aggregation in comparison with the previous case.

In detail, the transport model provided the generalised cost components of each origin-destination (OD) pair for four different travel purposes (work, study, leisure, and business trips) and, at the first logit stage, the transport modes considered were private and public. The number of passengers, for every mode on each OD pair, referred to daily movements inside the Lombardy Region and between Lombardy and Switzerland. In parallel, we developed a simplified transport model on a spreadsheet, to include it in the evaluation of other high-speed rail passengers originating from other Italian regions. For the characteristics of attracted users, in this secondary model, we considered a unique travel purpose (leisure) and car (as driver), car (as passenger), coach, HS train (plus shuttle bus interchange), and HS train (plus Malpensa express train interchange) as available transport modes. This model was calibrated using a Customer Satisfaction survey on Malpensa airport users realized in 2016 for SEA S.p.A.

In both models, each segment of the simulated mobility is associated with a set of calibrated $\beta$ coefficients (5), including the values of time (per trip purpose and per mode). To ensure results comparability, in the simplified model, we considered the same value of time for leisure purposes included in the regional transport model. Differently from the elaboration presented in the previous case study, no active modes were included in these simulations. Consequently, we were able to use directly generalised costs provided by models, thus ensuring the highest level of consistency with them. In addition, models give the quantities, in terms of daily passengers, for every mode on each OD pair, allowing us to calculate the users changing modes. Finally, model outputs, as in the previous case, also included data used to correct the monetary transfers in the CBA.

Overall, the output of the regional model consists of a database file with tables of attributes (generalised cost), quantities (amount of users), and transfers (fares, tolls, and taxes) per 238,210 origin-destination pairs and $8(2 \times 4)$ mode and travel purpose combinations. By means of SQL procedures, we estimated the surplus variation using the $\mathrm{RoH}$ method. Once the core calculations were done per OD pair, mode, and travel purpose, we proceeded with the aggregation of the results in 1,455 origin and destination zones, using the same zoning of the model. The same thing has been done for all attributes, quantities, and transfers. The simplified model is based on 50 origin-destination pairs corresponding to the relation between Malpensa airport and the main provincial capitals (and surrounding hinterlands) outside of the Lombardy Region; the final output referred to $2(2 \times 1)$ mode and travel purpose combinations; once the surplus calculation was done for each of the initial 5 transport modes, the results were aggregated in the private and public mode to ensure comparability with the regional model.

After the aggregation, the obtained data of both models have been interfaced with spreadsheet software for the CBA, and limited to regional model data, with a GIS software to produce cartographical representations of the main variables.

In total, eight final scenarios have been evaluated through this procedure. However, even if this number is definitely lower than the total scenario evaluated for the mobility plan, we take even more care to develop ad hoc debug procedures within the automation process.

This effort was necessary to allow a perfect interaction between the $\mathrm{RoH}$ method and the regional transport model output. In fact, while logit alone allows the introduction of "out-of-scale" generalised costs for nonexisting options (typically putting 9.999 in the generalised cost components), the $\mathrm{RoH}$ does not. In other words, both reference and postproject scenario have to be "feasible" for every existing combination of transport modes and travel purpose. Otherwise, if that alternative became feasible due to the project implementation, the $\mathrm{RoH}$ method will return unrealistic user surplus values.

This was initially the case of some OD pairs in the Lombardy transport model within the public mode (the use of public transport was capped to a maximum travel time of 2 hours), which were "not existing" (with a conventional 9.999 GC associated) before the project and "existing" (with a realistic GC associated) after. This produced wrong results that were pointed out thanks to the transposition of the results on a GIS software (other anomalies were detected in relation to incoherent railway station connectors and simulated service tariffs).

In comparison with the SUMP case, the Appraisal Summary Table has been split between financial and economic performances. The two analyses differ for how they treat user surplus and externality components (included in the economic CBA, but not in the financial one). Net Present 
Value (NPV) and Internal Rate of Return (IRR) have been calculated for both parts, while the Net Benefit over Investment Ratio (NBIR) and the Benefit Cost Ratio (B/C) are indicators only for the latter. In this stage, no budget constraint is foreseen and all actions are included. When, at latter stages, the available budget will be defined, these constraints can be managed consistently using appropriate algorithms [41]. Lastly, a separate tool for Risk Analysis was implemented to test the critical variables identified by the Sensitivity Analysis (for each scenario, investment costs, user surplus, externalities, and demand growth trends were tested). The term "critical variable" refers to those components for which a variation of $1 \%$ of their value leads to a percentage variation equal to or greater than the VANe $[21,22]$.

4.2.1. Scenarios. Previous to the assessment phase, public actors and stakeholders defined a set of 8 scenarios differing in terms of simulated demand (based on, resp., a conservative and optimistic growth in air passengers for the period 2016-2025), feasible rail projects and, consequently, different networks and supply.

In particular, in order to ensure faster connections between Milan and the airport, and thus possibly attracting both new demand and shifting the existing one from airport shuttle buses, decision-makers hypothesized to drop one of the two Milan stops (Milano Porta Garibaldi) from the airport express train.

Besides the main aim of ensuring a faster and more frequent connection with the airport, another political goal was to demonstrate quantitatively the necessity of redesigning or even deleting part of a correlated rail project, named "Potenziamento Rho-Gallarate e Raccordo Y." due to potential interferences in train circulations caused by the foreseen Y-shaped flat junction. This flat junction was approved by the national government in 2007 and inserted into the Strategic Infrastructure Program (PIS). The approval process did not require either an assessment or preliminary design phase due to the special condition allowed to the so-called "Legge Obiettivo", abrogated in 2016 (for critical aspects related to "Legge Obiettivo" projects see [42, 43]).

On the contrary, airport managers were mainly focused on enlarging the catchment area of the airport through adding, to the already forecasted suburban and regional supply [44], other market oriented rail services connecting the main regional and provincial Italian capitals.

Table 3 lists the scenarios that emerged from the consultation phase, with their main characteristics.

Each scenario was constructed starting from a "question," posed by decision-makers, which summarizes the different contexts in which the project could be realized or not. From a methodological point of view, all those services that, entirely or for part of their path, generate user benefits not directly connected to the project under assessment were considered invariants. Likewise, only the infrastructural investments necessary to ensure the supply remodelling envisaged were considered. Other projects, even if not yet realized, have been eventually considered as invariants between the reference and postproject scenarios.
4.2.2. Outputs and Results. In order to make the decision of the regional government more transparent and informed, the outputs of the assessment have been presented in a homogeneous and detailed way. Documents and analyses clarify all the relevant facts that should back the decisions, not limited to the sole aggregate CBA indicators (NPV, NBIR, B/C, and IRR). As for the previous case, results were presented through an Appraisal Summary Table (Figure 7) and a Book of Maps (Figure 8).

A particular care was taken with the scenario comparison, in order to enrich the undergoing debate between decisionmakers and stakeholders. Interestingly, results underline a series of critical aspects, common for all scenarios, that none of the actors had foreseen before.

First, the hypothesized network reconfiguration was considerably beneficial for regional users that move between the regional capital and its hinterland, but-unexpectedly-airport users were associated with a loss of surplus (from -0.01 to $-0.04 € /$ day per passenger) and with a shift from public transport to private car.

Thanks to the cartographical visualization of the phenomenon (Figure 8), it was clear how this particular result was a direct consequence of the new path envisaged for Malpensa express service. In fact, according to regional OD matrix data, almost $67 \%$ of users direct to and coming from the airport are generated/attracted by Milan. Thus, ensuring a faster connection from Milano Centrale station through cancelling the intermediate stop of Milano Porta Garibaldi implicates an increase in travel time, and eventually in the number of interchanges, for those users located in the southwest and northwest of Milan. Only those located in northeast areas obtain a reduction in travel time (for remaining zones, thanks to the existing metro network, the accessibility of these two stations are equivalent). Overall, the net effect for Milanese users is a loss in surplus in respect to the airport connection.

Secondly, the travel time reduction of 6 minutes for HS passengers proved to be not sufficient to promote a sensible modal shift in favour of the public transport mode (Figure 9). In fact, the increase in user surplus is almost completely related to the reduction of the number of interchanges (the ratio of $\beta^{\text {Interchange }}$ on $\beta^{\text {Cost }}$ shows that the perceived cost for each interchange is equal to $50 €$, suggesting that this typology of users considers a direct service more attractive than a connection similar in respect to travel time, but that implies even just an interchange). Consequently, on those OD pairs where a direct bus connection already exists, few users are attracted from the new HS service.

Lastly, both R_25|P_25s1 and R_25|P_25s2 scenarios, with a $\mathrm{B} / \mathrm{C}$ ratio, respectively, of 1.07 and 1.22 , show a limited improvement in consumer conditions in respect to project costs. Thus, it was not entirely possible to validate the thesis of the public decision-maker on the effectiveness of the first solution in comparison with the latter. However, this result is partially misleading because, due to the preliminary stage of project design, evaluations utilized feasible train timetables only for the new services envisaged. On the contrary, possible interferences with the already existing services were not considered. 
TABLE 3: Project scenarios.

\begin{tabular}{|c|c|c|c|c|c|c|c|}
\hline Scenario code & R_18* & P_18* & R_25* & P_25s1* & P_25s2* & P_25s0* & P_30* \\
\hline OD matrix horizon & 2015 & 2015 & $2025^{* *}$ & $2025^{* *}$ & $2025^{* *}$ & 2025 & $2025^{* *}$ \\
\hline \multicolumn{8}{|l|}{ Infrastructure components } \\
\hline Rail track T2 - Gallarate & & $\mathrm{x}$ & & $\mathrm{x}$ & & & $\mathrm{x}$ \\
\hline Y flat junction & & & & & & $\mathrm{x}$ & \\
\hline Y split-level junction & & & & & $\mathrm{x}$ & & \\
\hline Fourth rail track Rho-Parabiago & & & $\mathrm{x}$ & $\mathrm{x}$ & $\mathrm{x}$ & $\mathrm{x}$ & $\mathrm{x}$ \\
\hline Fourth rail track Parabiago- Gallarate & & & & & & & $\mathrm{x}$ \\
\hline \multicolumn{8}{|l|}{ Forecasted rail services and frequency } \\
\hline $\begin{array}{l}\text { Malpensa Express (Milan - Saronno - } \\
\text { Terminal 2) }\end{array}$ & $30^{\prime}$ & & $30^{\prime}$ & & & $60^{\prime}$ & \\
\hline $\begin{array}{l}\text { Malpensa Express (Milano - Saronno - } \\
\text { Terminal } 2 \text { - Gallarate) }\end{array}$ & & $30^{\prime}$ & & & & & \\
\hline $\begin{array}{l}\text { Malpensa Express (Milano - Rho - } \\
\text { Gallarate - Terminal 1) }\end{array}$ & & & & $30^{\prime}$ & & & $15^{\prime}$ \\
\hline $\begin{array}{l}\text { Malpensa Express (Milano - Rho - Y } \\
\text { junction - Terminal 2) }\end{array}$ & & & & & $30^{\prime}$ & $60^{\prime}$ & \\
\hline $\begin{array}{l}\text { Regional train (Bergamo - Saronno - } \\
\text { Gallarate) }\end{array}$ & $60^{\prime}$ & & $60^{\prime}$ & & $60^{\prime}$ & $60^{\prime}$ & \\
\hline $\begin{array}{l}\text { Regional train (Bergamo - Saronno - } \\
\text { Gallarate - Terminal 1) }\end{array}$ & & $60^{\prime}$ & & $60^{\prime}$ & & & $60^{\prime}$ \\
\hline Suburban train S9 (Albairate - Saronno) & $30^{\prime}$ & $30^{\prime}$ & & & & & \\
\hline $\begin{array}{l}\text { Suburban train S9 (Albairate - Saronno - } \\
\text { Busto Arsizio) }\end{array}$ & & & $30^{\prime}$ & $30^{\prime}$ & $30^{\prime}$ & $30^{\prime}$ & \\
\hline $\begin{array}{l}\text { Suburban train S9 (Albairate - Saronno - } \\
\text { Busto Arsizio - Gallarate - Terminal 1) }\end{array}$ & & & & & & & $30^{\prime}$ \\
\hline Suburban train S15 (Milan - Parabiago) & & & $30^{\prime}$ & $30^{\prime}$ & $30^{\prime}$ & $30^{\prime}$ & \\
\hline $\begin{array}{l}\text { Suburban train S15 (Milan - Parabiago - } \\
\text { Gallarate - Terminal 1) }\end{array}$ & & & & & & & $30^{\prime}$ \\
\hline $\begin{array}{l}\text { HS train (Multiple Origins - Milan - } \\
\text { Saronno - Terminal 2) }\end{array}$ & & & Spot & & & Spot & \\
\hline $\begin{array}{l}\text { HS train (Multiple Origins - Milan - } \\
\text { Gallarate - Terminal 1) }\end{array}$ & & & & Spot & & & Spot \\
\hline $\begin{array}{l}\text { HS train (Multiple Origins - Milan - Rho } \\
\text { - Y junction - Terminal 2) }\end{array}$ & & & & & Spot & Spot & \\
\hline
\end{tabular}

From this analysis, decision-makers decided to allow the progress of the infrastructural project to the next design phase and, at the same time, to prepare further checks aimed at optimizing network supply.

\section{Conclusions}

Cost-benefit analysis and public expenditure assessment techniques are broadly studied in literature. However, some relevant aspects of evaluation, especially related to the practical application in complex cases and to the effective inclusion of CBA in the policy design process, remain unsolved.

The primary objective of this paper is to give indications about how to correctly evaluate, using Cost-Benefit Analysis, complex urban mobility plans and infrastructural projects.
This need is more and more actual, given the increasing shift of mobility planning practices [1] from a single infrastructure to complex and consistent urban plans, to take advantage of the benefits of policy packaging [2].

To reach this goal, once a transport model is available, it is convenient to extract the needed data from the chosen model and to adopt, depending on whether nonadditive policies are included in the simulation or not, either the Rule of Half or logsum methods for consumer surplus calculation.

Another objective of the paper deals with the enrichment of the outputs to allow a better evaluation. Thanks again to the integration with a transport model, it is possible to provide a geographical and social distributive analysis, spatially depicting the effects on consumer surplus, and of envisaged actions, policies, and projects. This tool could potentially be applied also to spatially represent other variables (such as safety or 


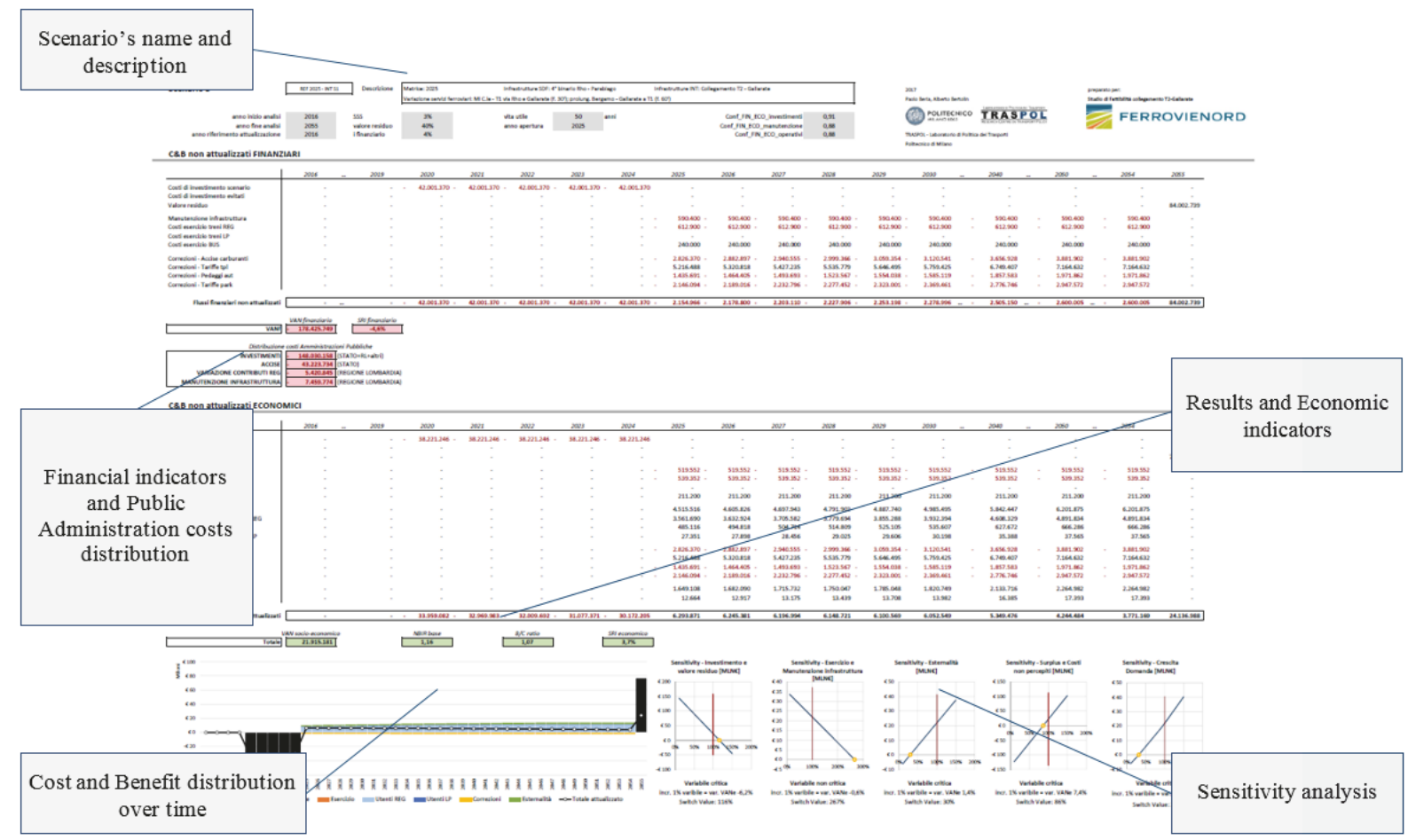

Figure 7: An example of Appraisal Summary Table organisation.

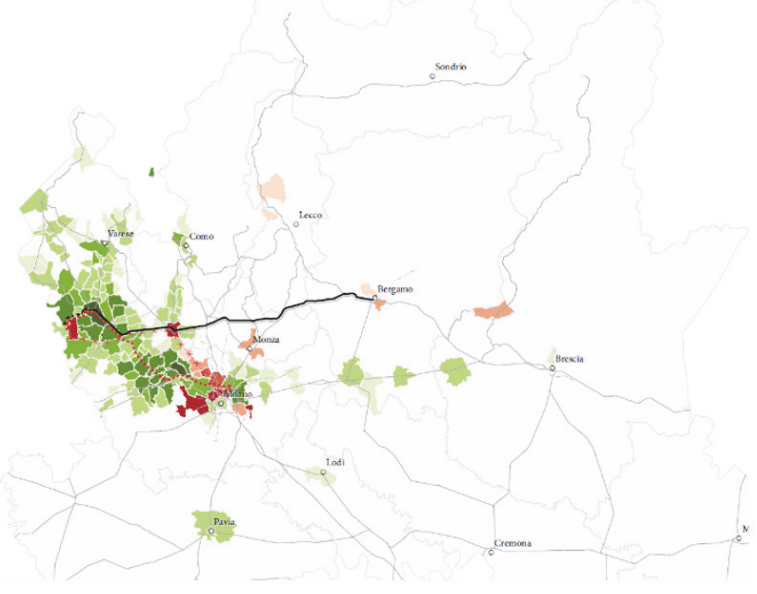

(a)

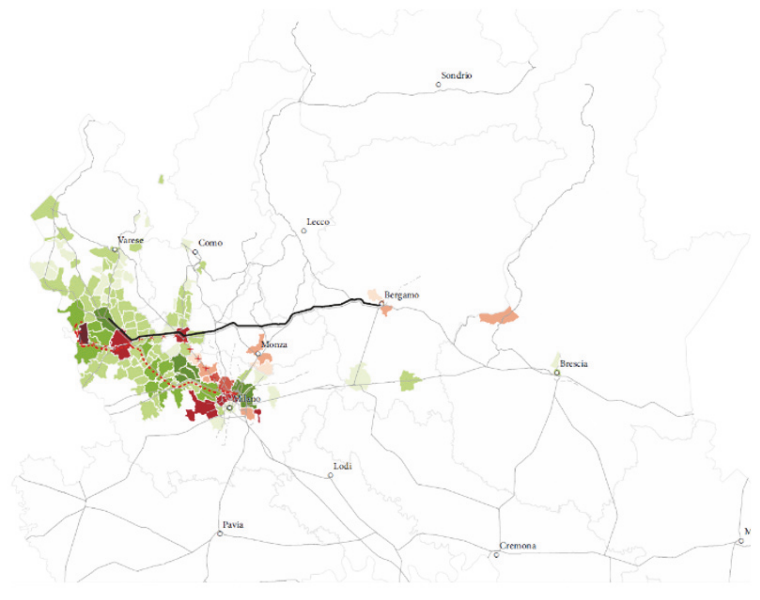

(b)

FIgURE 8: Total variation in user surplus. (a) Scenario R_25|P_25s1; (b) scenario R_25|P_25s2.

environmental benefits). However, in order to carry out this type of analysis, a deeper interaction with the transport model is needed. In particular, information on the different paths between OD pairs have to be collected from the fourth step of the transport model ("route assignment" phase).

A second possible output to effectively represent and communicate the results of the evaluation is the Appraisal Summary Table. Both tools, by improving results readability, can help politicians, policy-makers, stakeholders, and citizens to correctly understand project and plan effects and in general improve the transparency and the awareness of the choices taken.

In particular, through the description of two operative case studies, we show evidence on how these two tools can provide a significant support to decision-makers: by quantitatively demonstrating how, in mature networks, smaller actions have a systematically higher efficiency than large and expensive projects (SUMP case study) and by unearthing possible critical aspects of the envisaged network supply (Malpensa airport rail connection case study). 


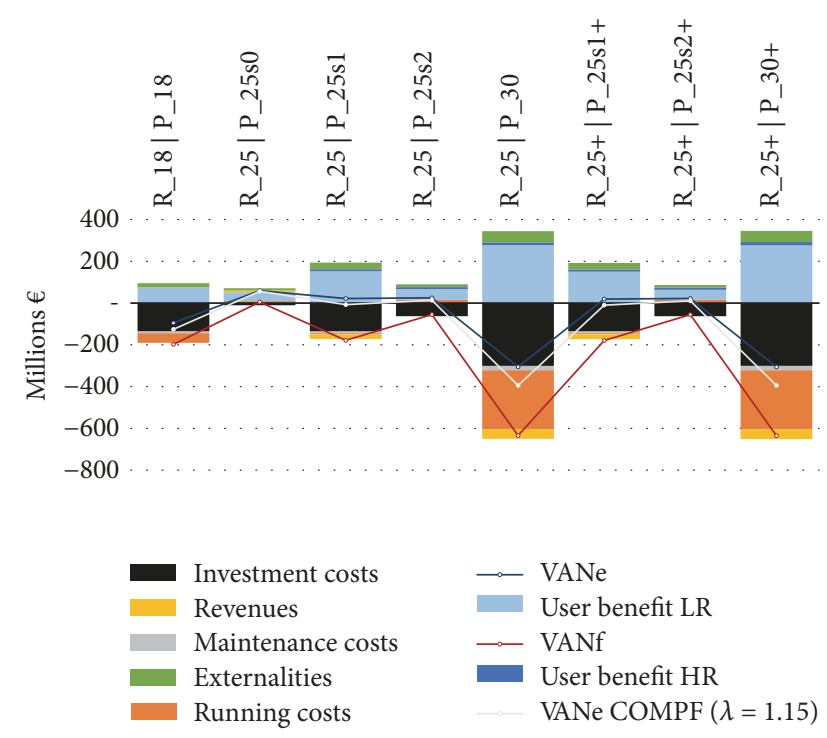

FIgURE 9: CBA compact indicators and costs distribution.

Lastly, these tools can be also a part of a debug procedure of the transport model itself, thus providing hints on how to return more consolidated results from the simulation point of view.

\section{Additional Points}

Highlights. (i) Traditional CBA can also be applied to the evaluation of complex transport plans. (ii) We revised the ways to calculate consumer surplus: generalised costs comparison, Rule of Half, and logsum. (iii) We comment on advantages and limits of both methods, suggesting when logsum has to be preferred to the Rule of Half. (iv) We show how CBA can be integrated with transport models. (v) Interaction with decision-makers can be improved by using spatial distributive analysis.

The attribution of the different sections is the following: Sections 1, 2, 3, and 4.1 have been written by Paolo Beria and Raffaele Grimaldi and were originally included in the working paper Beria \& Grimaldi [23]. Alberto Bertolin is also the author of the remaining sections.

\section{Conflicts of Interest}

The authors declare that there are no conflicts of interest regarding the publication of this paper. Since September 2017, Raffaele Grimaldi has been employed at Autorità di Regolazione dei Trasporti (the Italian transport regulation authority), but this article presents the results of former research and does not represent the views of the authority.

\section{Acknowledgments}

The research is part of the project "QUAINT" (protocol: RBSI14JR1Z), supported by the Italian Ministry of Education
University and Research (MIUR), within the SIR programme (DD no. 197 del 23 gennaio 2014).

\section{References}

[1] Eltis, Developing and implementing a Sustainable Urban Mobility Plan. Guidelines, Prepared for the European Commission Directorate-General for Mobility and Transport, Brussels, Belgium, 2013.

[2] M. Givoni, "Addressing transport policy challenges through policy-packaging," Transportation Research Part A: Policy and Practice, vol. 60, pp. 1-8, 2014.

[3] EC (2013). Together towards competitive and resource-efficient urban mobility. $\operatorname{COM}(2013) 913$ final. Communication from the Commission to the European Parliament, the Council, the European Economic and Social Committee and the Committee of the Regions. Brussels, Belgium.

[4] D. Banister, "The sustainable mobility paradigm," Transport Policy, vol. 15, no. 2, pp. 73-80, 2008.

[5] A. L. Bristow and J. Nellthorp, "Transport project appraisal in the European Union," Transport Policy, vol. 7, no. 1, pp. 51-60, 2000.

[6] P. Bickel, R. Friedrich, A. Burgess, P. Fagiani, A. Hunt, and G. De Jong, Developing Harmonised European Approaches for Transport Costing and Project Assessment (HEATCO). Deliverable D6: Case Study Results, University of Stuttgart, 2006.

[7] P. Beria, M. Giove, and M. Miele, "A comparative analysis of assessment approaches. Six cases from europe," International Journal of Transport Economics, vol. 39, no. 2, pp. 185-217, 2012.

[8] P. Beria, I. Maltese, and I. Mariotti, "Multicriteria versus Cost Benefit Analysis: A comparative perspective in the assessment of sustainable mobility," European Transport Research Review, vol. 4, no. 3, pp. 137-152, 2012.

[9] D. Tsamboulas, G. S. Yiotis, and K. D. Panou, "Use of multicriteria methods for assessment of transport projects," Journal of Transportation Engineering, vol. 125, no. 5, pp. 407-414, 1999.

[10] G. Marsden and C. Snell, "The role of indicators, targets and monitoring in decision-support for transport," European Journal of Transport and Infrastructure Research, vol. 9, no. 3, pp. 219-236, 2009.

[11] A. Tudela, N. Akiki, and R. Cisternas, "Comparing the output of cost benefit and multi-criteria analysis: An application to urban transport investment," Transportation Research Part A: Policy and Practice, vol. 40, no. 5, pp. 414-423, 2006.

[12] T. Sager, "The comprehensiveness dilemma of cost-benefit analysis," European Journal of Transport and Infrastructure Research, vol. 13, no. 3, pp. 169-183, 2013.

[13] S. Damart and B. Roy, "The uses of cost-benefit analysis in public transportation decision-making in France," Transport Policy, vol. 16, no. 4, pp. 200-212, 2009.

[14] A. L. Bristow, P. J. Mackie, J. Nellthorp, and G. D. Jansen, "Costs, prices and values in the appraisal of transport projectsEuropean principles and practice," in Proceedings of the Eighth World Conference in Transport Research, Antwerp, Belgium, 1998.

[15] J. Nellthorp, S. Grant-Muller, H. Chen et al., "Comparing the economic performance and environmental impact of TransEuropean Road Networks: the EUNET assessment tool,' in Proceedings of the Second European Road Research Conference, Brussels, Belgium, June 1999.

[16] D. G. Regio, Guide to Cost-Benefit Analysis of investment projects. Structural Funds, Cohesion Fund and Instrument for 
Pre-Accession, Directorate General Regional Policy. European Commission, 2008.

[17] EC-EIB, RAILPAG: Railway Project Appraisal Guidelines, European Commission - European Investment Bank, 2004.

[18] D. Browne and L. Ryan, "Comparative analysis of evaluation techniques for transport policies," Environmental Impact Assessment Review, vol. 31, no. 3, pp. 226-233, 2011.

[19] S. Maffii and R. Parolin, "Estimating benefits for modal shifters: a methodological remark," in Selected Proceedings of the 13rd World Conference on Transport Research, 2013.

[20] R. Grimaldi and P. Beria, "Open issues in the practice of cost benefit analysis of transport projects," in Proceedings of the 13rd World Conference on Transport Research, 2013.

[21] MIT, Linee Guida per la valutazione degli investimenti in opere pubbliche nei settori di competenza del Ministero delle Infrastrutture e dei Trasporti ai sensi del D. Lgs. 228/2011. Ministero delle Infrastrutture e dei Trasporti - Direzione Generale per lo sviluppo del territorio, la programmazione ed i progetti internazionali e Nucleo di Valutazione e Verifica degli Investimenti Pubblici (NVVIP). 2016.

[22] Regione Lombardia, Linee Guida per la redazione di Studi di Fattibilità, Interventi Infrastrutturali, Milano, Italy, 2015.

[23] P. Beria and R. Grimaldi, "Cost Benefit Analysis to assess urban mobility plans. Consumers' surplus calculation and integration with transport models," Working Paper, 2014.

[24] J. E. Stiglitz, Economics of the Public Sector, W. W. Norton \& Company, 3rd edition, 2000.

[25] E. Cascetta, Teoria e Metodi della Ingegneria Dei Sistemi Di Trasporto, Torino, Italy, 1998.

[26] J. Ortúzar and L. G. Willumsen, Modelling Transport, John Wiley \& Sons, Chichester, UK, 1990.

[27] E. Cascetta, Modelli per i Sistemi di Trasporto: Teoria e Applicazioni, UTET, Torino, Italy, 2006.

[28] G. De Jong, M. Pieters, A. Daly, I. Graafland, E. Kroes, and C. Koopmans, Using the Logsum as an Evaluation Measure. Literature and Case Study, RAND Europe Working Paper. Prepared for AVV Transport Research Centre, Leiden, The Netherlands, 2005.

[29] G. de Jong, A. Daly, M. Pieters, and T. van der Hoorn, "The logsum as an evaluation measure: Review of the literature and new results," Transportation Research Part A: Policy and Practice, vol. 41, no. 9, pp. 874-889, 2007.

[30] P. Brunton, Transport User Benefits: An Alternative to the Rule of Half, AECOM, 2012.

[31] J. Bates, "Economic evaluation and transport modelling: theory and practice," in Moving through Nets: The Physical and Social Dimensions of Travel, pp. 279-351, 2006.

[32] S. Maffii, R. Parolin, M. Brambilla, and R. Scatamacchia, TRACECA Appraisal Manual. Guidelines for Pre-Feasibility of Transport Projects with Exercises and Case Studies. A project implemented by TRT Trasporti e Territorio in association with Alfen Consult, Dornier Consulting and PTV, for the TRACECA IDEA project. 2012.

[33] K. Geurs, B. Zondag, G. de Jong, and M. de Bok, "Accessibility appraisal of land-use/transport policy strategies: More than just adding up travel-time savings," Transportation Research Part D: Transport and Environment, vol. 15, no. 7, pp. 382-393, 2010.

[34] J. Castiglione, J. Freedman, and W. Davidson, Application of a Tour-Based Microsimulation Model to a Major Transit Investment, San Francisco County Transportation Authority and PB Consult, San Francisco, Calif, USA, 2003.
[35] AMAT, Piano Urbano della Mobilità Sostenibile (PUMS), Agenzia Mobilità Ambiente e Territorio, Milano, Italy, 2015.

[36] AMAT, Piano Urbano della Mobilità Sostenibile (PUMS) Rapporto ambientale, Agenzia Mobilità Ambiente e Territorio, Milano, Italy, 2016.

[37] DfT, Transport Analysis Guidance (TAG). An Overview of Transport Appraisal, Department for Transport, UK, 2014.

[38] PWC, "Evaluation of the costs and benefits to the community of financial investment in cycling programs and projects in New South Wales," Final Report. Prepared for: Roads and Traffic Authority of NSW and the Department of Environment and Climate Change, Australia, 2009.

[39] TemaNORD, CBA of Cycling, Nordic Council of Ministers, Copenhagen, Denmark, 2005.

[40] DfT, NATA Refresh: Appraisal for a Sustainable Transport System, Department for Transport, UK, 2009.

[41] A. Bonnafous and P. Jensen, "Ranking transport projects by their socioeconomic value or financial internal rate of return?" Transport Policy, vol. 12, no. 2, pp. 131-136, 2005.

[42] SIPoTra, "Quale futuro per la politica dei trasporti dopo il nuovo codice degli appalti," I quaderni di SIPoTra 1/2017, 2017.

[43] C. Virno, Se alle grandi opere mancano le fondamenta. Della valutazione, 2005, http://www.lavoce.info/archives/22976/se-allegrandi-opere-mancano-le-fondamenta-della-valutazione/.

[44] Regione Lombardia, "Programma Regionale Mobilità e Trasporti (PRMT)," Struttura Programma Regionale della Mobilità e dei Trasporti - DG Infrastrutture e Mobilità, Milano, Italy, 2016. 


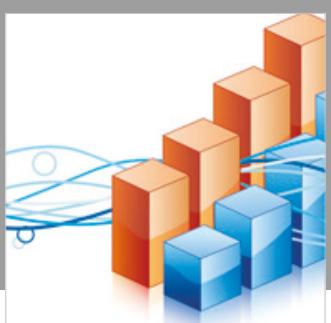

Advances in

Operations Research

\section{-n-m}
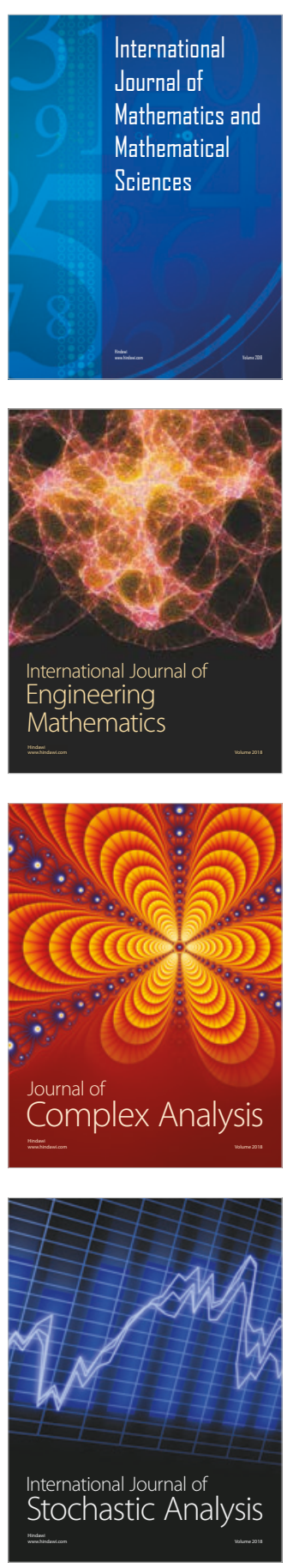
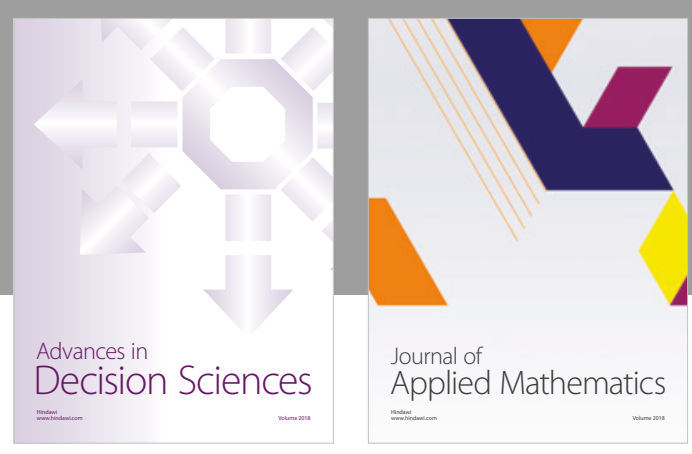

Journal of

Applied Mathematics
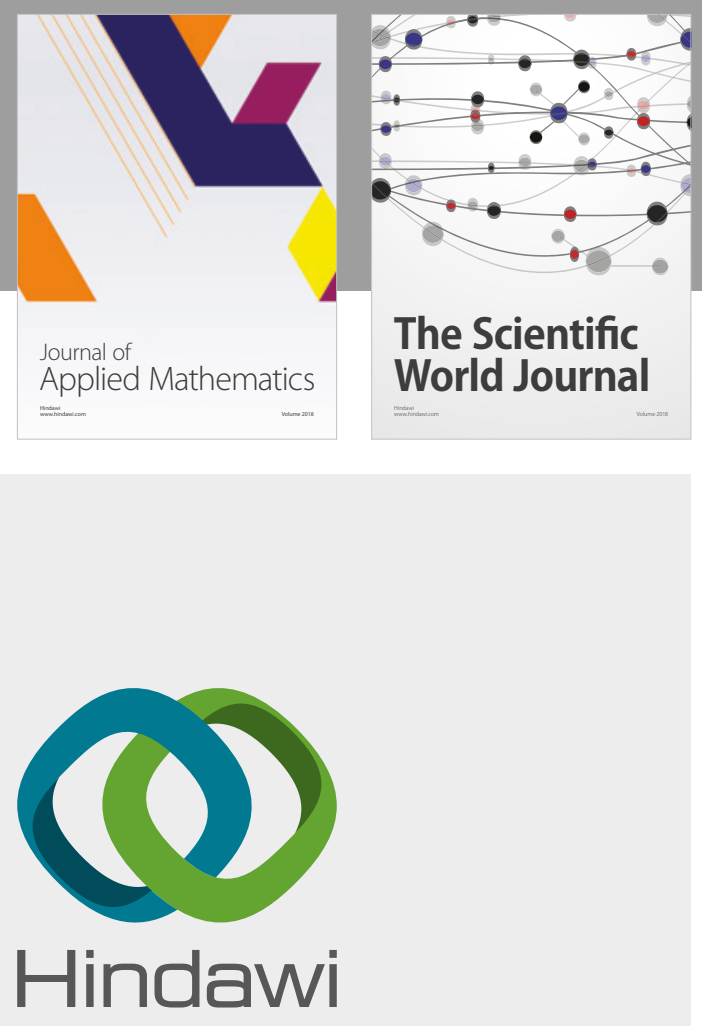

Submit your manuscripts at

www.hindawi.com

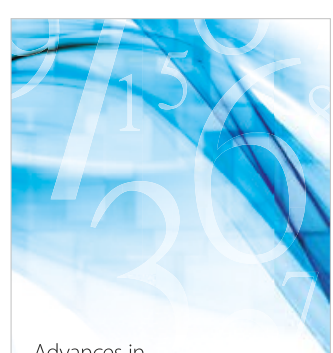

Advances in
Numerical Analysis
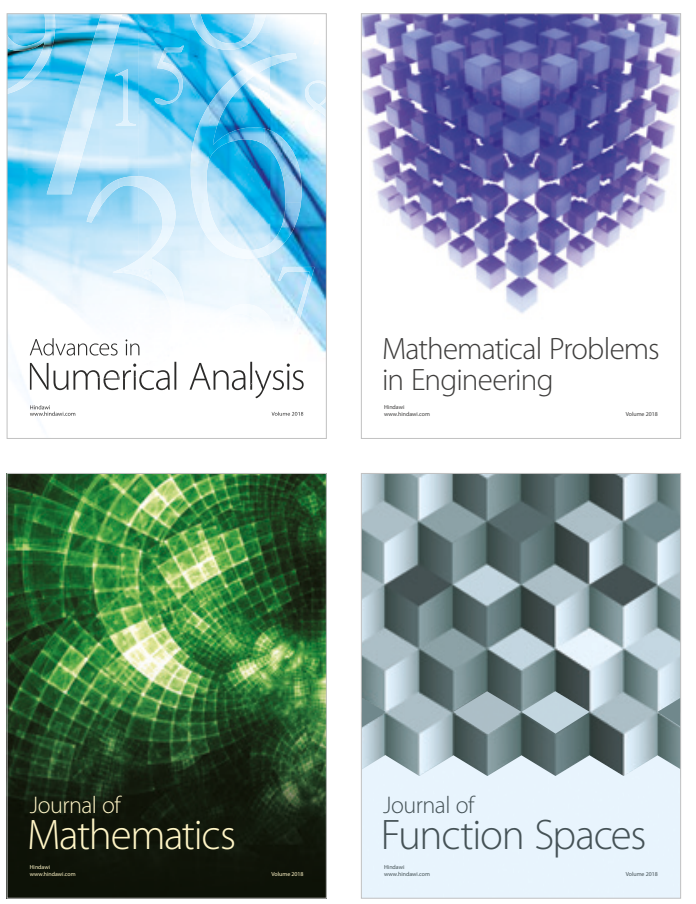

Mathematical Problems in Engineering

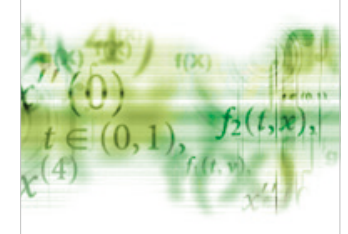

International Journal of

Differential Equations

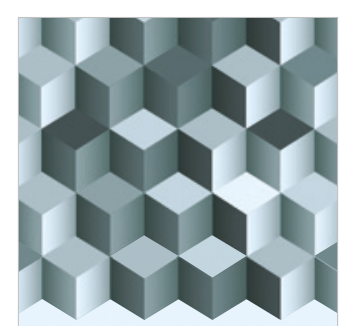

Journal of

Function Spaces

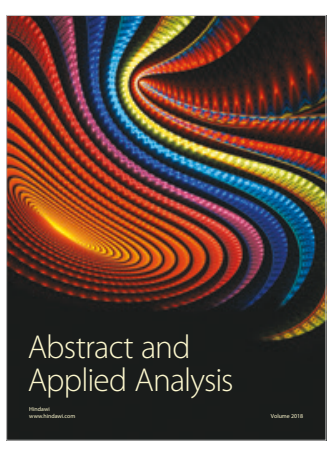

The Scientific

World Journal

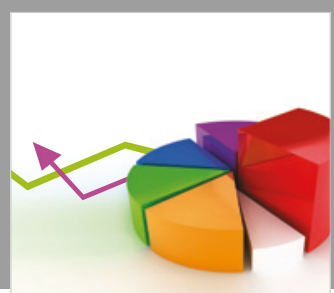

Journal of

Probability and Statistics
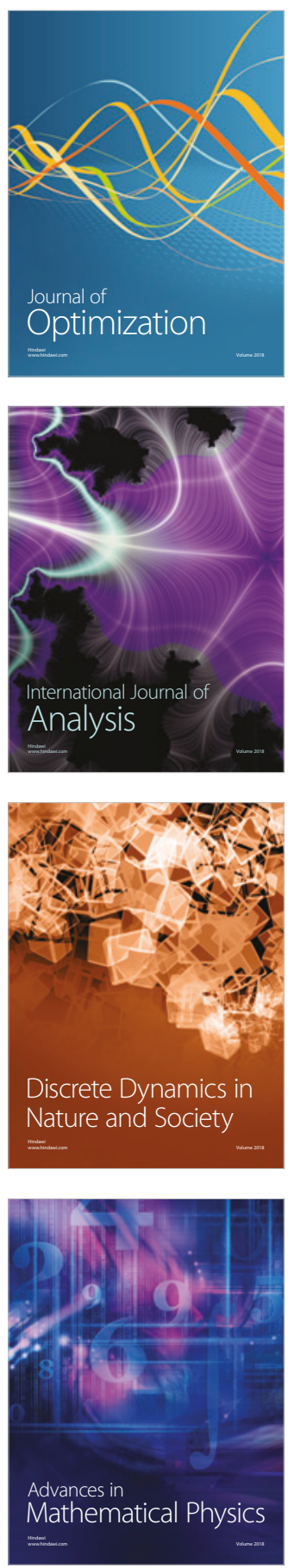